\title{
Short-term tocolytics for preterm delivery - current perspectives
}

\author{
This article was published in the following Dove Press journal: \\ International Journal of Women's Health \\ 27 March 2014 \\ Number of times this article has been viewed
}

\section{David M Haas \\ Tara Benjamin \\ Renata Sawyer \\ Sara K Quinney \\ Department of Obstetrics and Gynecology, Indiana University School of Medicine, Indianapolis, IN, USA}

Correspondence: David M Haas Indiana University School of Medicine, 550 N University Blvd, UH2440, Indianapolis, IN 46202, USA

Tel + I 3179448609

Email dahaas@iupui.edu
Abstract: Administration of short-term tocolytic agents can prolong pregnancy for women in preterm labor. Prolonging pregnancy has many benefits because it allows for other proven interventions, such as antenatal corticosteroid administration, to be accomplished. This review provides an overview of currently utilized tocolytic agents and the evidence demonstrating their efficacy for prolonging pregnancy by at least 48 hours. General pharmacological principles for the clinician regarding drugs in pregnancy are also briefly discussed. In general, while the choice of the best first-line short-term tocolytic drug is not clear, it is evident that use of these agents has a clear place in current obstetric therapeutics.

Keywords: tocolytics, short-term, preterm delivery

\section{Introduction}

Preterm birth continues to be a problem for obstetricians. Almost one in eight babies in the USA is born before 37 weeks' gestational age. ${ }^{1}$ Although the causes of preterm labor are not well understood, the burden of preterm birth is clear. ${ }^{2}$ The majority of neonatal deaths and over one third of infant deaths are linked to preterm birth. ${ }^{3,4}$ In addition, the health care costs of prematurity are steep..$^{5,6}$ This is particularly true for births before 28 weeks.

Given that methods to predict and prevent preterm birth are imperfect, attention focuses on the treatment of the woman admitted in preterm labor. The most beneficial intervention in these cases is antenatal corticosteroids. Antenatal corticosteroids have been clearly demonstrated to reduce neonatal mortality and multiple morbidities. ${ }^{7}$ Thus, the primary goal of tocolytic therapy has been to maintain the pregnancy for at least 48 hours to enable administration of antenatal corticosteroids, more recently magnesium sulfate for neuroprotection, and possibly maternal transport to a tertiary care facility. No evidence exists that tocolytic therapy directly benefits neonatal outcomes. ${ }^{2}$ However, short-term tocolytic therapy has been demonstrated to be superior to placebo in prolonging pregnancy for at least 48 hours. ${ }^{8,9}$

The objective of this review is to summarize the evidence regarding tocolytic drugs used for short-term prolongation of pregnancy. Table 1 shows the commonly used tocolytic drug classes and some of the common side effects. We will also review some general pharmacological considerations of drug therapy in pregnancy related to tocolytic drugs.

\section{Betamimetics}

Terbutaline is the $\beta 2$-adrenergic agonist most commonly used in obstetrics in the USA although ritodrine was most extensively studied and is the only agent approved 
Table I Commonly used tocolytic drug classes

\begin{tabular}{|c|c|c|c|}
\hline Drug class & $\begin{array}{l}\text { Individual drugs in the class } \\
\text { commonly used or studied }\end{array}$ & Major side effects & Comments \\
\hline Betamimetics $^{18}$ & $\begin{array}{l}\text { Ritodrine, terbutaline, } \\
\text { hexoprenaline, salbutamol }\end{array}$ & $\begin{array}{l}\text { Cardiac arrhythmias (tachycardia), } \\
\text { hypotension, hyperglycemia, } \\
\text { pulmonary edema }\end{array}$ & $\begin{array}{l}\text { Long-term use recently given } \\
\text { an FDA “black box" warning }\end{array}$ \\
\hline $\begin{array}{l}\text { Calcium channel } \\
\text { blockers }^{19}\end{array}$ & Nifedipine, nicardipine & Maternal hypotension, dizziness & Initial loading dose common \\
\hline Magnesium sulfate ${ }^{25}$ & Magnesium sulfate & $\begin{array}{l}\text { Flushing, respiratory suppression, } \\
\text { cardiac arrest }\end{array}$ & $\begin{array}{l}\text { Currently utilized for } \\
\text { neuroprotection protocols }\end{array}$ \\
\hline $\begin{array}{l}\text { Oxytocin receptor } \\
\text { blockers }^{28}\end{array}$ & Atosiban, barusiban & Gastrointestinal upset & Not utilized in the USA \\
\hline Prostaglandin inhibitors ${ }^{29}$ & $\begin{array}{l}\text { Indomethacin, sulindac, } \\
\text { celecoxib }\end{array}$ & $\begin{array}{l}\text { Maternal gastrointestinal disturbance, } \\
\text { oligohydramnios, premature } \\
\text { constriction of the ductus }\end{array}$ & $\begin{array}{l}\text { Concern about ductal } \\
\text { constriction limits use generally } \\
\text { to }<32 \text { weeks' gestation }\end{array}$ \\
\hline Nitrates and others ${ }^{30}$ & Nitroglycerin, nitric oxide & $\begin{array}{l}\text { Headache, flushing, maternal } \\
\text { hypotension, tachycardia }\end{array}$ & $\begin{array}{l}\text { Currently limited to research } \\
\text { trials }\end{array}$ \\
\hline
\end{tabular}

Abbreviation: FDA, US Food and Drug Administration.

for tocolysis by the US Food and Drug Administration (FDA). Ritodrine, however, is no longer marketed in the USA. Other agents, including albuterol, fenoterol, hexoprenaline, metaproterenol, nylidrin, and orciprenaline have been used for tocolysis worldwide. ${ }^{10}$ Given the recent FDA warning in regard to the maternal and possible neonatal side effects of terbutaline, ${ }^{11}$ the frequency of its use is likely decreasing. Betamimetics exert their stimulatory effect on $\beta 2$ receptors. By increasing cyclic AMP, they deplete intracellular calcium levels, diminishing myometrial contractility. Interestingly, the concentration of $\beta 2$ receptors appears to gradually decrease with time during tocolysis, leading to a form of desensitization (tachyphylaxis), ${ }^{12}$ which supports only a short duration of action and use of these agents.

The subcutaneous route of administration is most commonly used for terbutaline. The typical dose is $0.25 \mathrm{mg}$, which can be repeated every 4 hours..$^{10}$ Continuous intravenous infusion of terbutaline is rarely used. According to the FDA, the oral route is contraindicated in the treatment or prevention of preterm labor. ${ }^{11}$ Use of a $\beta 2$-adrenergic agonist in pregnancy is not without maternal or fetal side effects. The recent FDA warning concerns serious (albeit rare) maternal side effects. Terbutaline also binds to $\beta 1$ receptors at multiple sites and may lead to maternal tachycardia and hypotension as well as relaxation of the bronchial tree. Women may complain of palpitations, shortness of breath, tremors, headache, and nasal congestion. Hypokalemia and hyperglycemia may also develop. ${ }^{13}$ Use of terbutaline may also be associated (albeit rarely) with pulmonary edema and symptomatic arrhythmias. ${ }^{14}$ Myocardial infarction and death have been reported. ${ }^{15}$ Terbutaline is contraindicated in women with heart disease, tachycardia over 120 beats per minute, hemorrhage, or hypovolemia. Neonatal hypoglycemia, hypocalcemia, and ileus may occur after treatment with betamimetics and can be clinically significant if maternal infusion is not discontinued 2 hours or more before delivery. ${ }^{10}$ It is unclear whether there is a relationship between tocolysis with $\beta 2$-agonists and risk of neonatal intraventricular hemorrhage. The majority of investigators in retrospective studies could not confirm this relationship. ${ }^{16,17}$

A Cochrane review of 1,332 patients enrolled in eleven randomized, placebo-controlled trials of $\beta 2$-agonists demonstrated that treated women were less likely to deliver within 48 hours (relative risk [RR] 0.63; confidence interval [CI] $0.53-0.75$ ) but not within 7 days. ${ }^{13}$ Perinatal mortality and neonatal morbidity were not reduced in these populations. A recent systematic review and network meta-analysis of 95 randomized controlled trials investigating tocolytic therapy concluded that the probability of delivery being delayed by at least 48 hours with $\beta 2$-agonists had an odds ratio of 2.41 (95\% credible interval 1.27-4.55) compared with placebo. No improvement in neonatal outcomes was demonstrated over placebo. Side effects requiring a change of agent were highest for $\beta 2$-agonists (OR 22.68, 95\% CI 7.51 to 73.67 ). ${ }^{8}$ Given the adverse effect profile, however, betamimetic use is limited in labor and delivery units.

\section{Calcium channel blockers}

Dihydropyridine calcium channel blockers, eg, nifedipine and nicardipine, act on L-type calcium channels to inhibit calcium influx into myometrial cells. Reduced intracellular calcium concentrations prevent activation of myosin light chain kinase, and thereby myometrium contraction. 
While the route and dosage regimen of nifedipine differs between studies, most administer oral or sublingual loading doses of 10-30 mg immediate-release nifedipine, repeated every 15-20 minutes for the first hour followed by 10-20 mg orally every $4-8$ hours. ${ }^{18}$ Adverse events associated with nifedipine are usually mild and related to peripheral vasodilation, eg, flushing. In normotensive women with no underlying heart disease, there is typically minimal effect on blood pressure due to a compensatory rise in heart rate and stroke volume. If hypotension occurs, it is typically within the first few hours after initiation and is more likely when nifedipine is administered sublingually. ${ }^{19}$ Other adverse events, most of which occur rarely and in women with other risk factors, include pulmonary edema, dyspnea, and myocardial infarction. ${ }^{19}$

Nifedipine is the most commonly studied calcium channel blocker, and several meta-analyses support its effectiveness for acute tocolysis. A Cochrane review of calcium channel blockers for acute tocolysis, including 12 randomized controlled trials of 1,029 patients, found that these agents were effective in delaying birth for 7 days and past 34 weeks' gestation. ${ }^{20}$ A more recent meta-analysis,,${ }^{18}$ including 26 studies of 2,179 women, found no difference between nifedipine and other tocolytics in delaying birth at 48 hours. However, women treated with nifedipine were less likely to deliver within 7 days and more likely to deliver at $>37$ weeks' gestation than those taking $\beta 2$-adrenergic receptor antagonists. Nifedipine was associated with fewer maternal adverse events than other tocolytics. ${ }^{18} \mathrm{~A}$ recent decision analysis and network meta-analysis both found that calcium channel blockers would be the preferred first-line tocolytic with regard to several important outcomes. ${ }^{8,9}$

\section{Magnesium sulfate}

Because of its familiarity and presumed safety, magnesium sulfate has been a mainstay of tocolytic therapy since $1971 .^{21}$ Proposed mechanisms of action include competition with calcium at motor end plates and/or at plasma membrane voltage-gated channels. Antagonizing calcium at the motor end plate prevents release of acetylcholine into the synaptic cleft and transmission of excitation. Obstructing calcium at plasma membrane voltage-gated channels prevents its intracellular influx and activation of myosin light chain kinase which is required for myometrial contractility.

Magnesium sulfate must be administered intravenously to attain therapeutic levels. A loading dose of 4-6 g in $10 \%-20 \%$ solution over 30 minutes is followed by a continuous infusion of $2 \mathrm{~g}$ per hour. ${ }^{22}$ The therapeutic effect does not rely on serum magnesium levels because mean serum levels have been found to be similar between patients with successful and failed tocolysis. ${ }^{23}$ The infusion rate is titrated until a maximum of $4 \mathrm{~g}$ /hour is reached or until the patient has less than one contraction per 10 minutes. Calcium gluconate should be readily available for reversal of any toxic side effects. Maintenance therapy is sometimes continued until the antenatal steroid course is completed. ${ }^{24}$ Maternal side effects with magnesium sulfate therapy can range from mild (eg, flushing and somnolence) to severe (eg, respiratory depression and cardiac arrhythmias).

A 2012 network meta-analysis of tocolytics showed probabilities of magnesium sulfate being ranked in the top three most efficacious classes and the bottom three or least efficacious classes of $63 \%$ and $5 \%$, respectively. ${ }^{8}$ A systematic review comparing magnesium sulfate with no treatment or placebo demonstrated that magnesium sulfate did not significantly reduce the risk of birth within 48 hours (RR 0.75 , 95\% CI 0.54-1.03), and despite limitations in study design, further concluded that there was no evidence of magnesium sulfate having a clinically important tocolytic effect. ${ }^{25}$ This same review assessed 15 comparative trials, but must be interpreted with caution because of inadequate power to evaluate equivalence among tocolytics and detected no differences between the effectiveness of magnesium sulfate and other tocolytics. For delivery within 48 hours of initiation of treatment, summary risk ratios were: magnesium versus betaadrenergic agonists (RR 1.23, 95\% CI 0.70-2.17), versus calcium channel blockers (RR 1.06, 95\% CI 0.63-1.78), versus cyclooxygenase inhibitors (RR $0.84,95 \% \mathrm{CI}$ 0.49-1.45), and versus any control, whether active or placebo (RR 0.90, 95\% CI 0.72-1.13). ${ }^{25}$ Magnesium sulfate has seen a resurgence in use due to the documented neuroprotective effect for the preterm infant, but that is outside the scope of this review. ${ }^{2}$

\section{Oxytocin receptor blockers}

Atosiban, a selective oxytocin/vasopressin receptor antagonist, is available for clinical use in Europe, but not in the USA. The end point of the mechanism of action of atosiban is similar to that of $\beta 2$-agonists, ie, a decrease in intracellular calcium and therefore inhibition of myometrial contraction. This is accomplished by blockade of oxytocin receptors, preventing oxytocin-induced conversion of phosphatidylinositol to inositol triphosphate and release of calcium into the cytoplasm.

Atosiban is an intravenous agent administered as a bolus of $6.75 \mathrm{mg}$ over one minute followed by a continuous infusion 
at $18 \mathrm{mg} /$ hour for a period of 3 hours, and then $6 \mathrm{mg} /$ hour for up to 45 hours. ${ }^{26}$ Atosiban appears to have a good maternal safety profile, with rare and non-life-threatening side effects, the most common being hypersensitivity and injection siterelated reactions.

A concern was raised in one randomized trial about a possible association between atosiban and fetal death in very premature infants. ${ }^{27} \mathrm{~A}$ trend towards a higher rate of extremely premature fetal-neonatal deaths was noted in women randomized to atosiban. However, there were significant confounders present and randomization was not stratified based on gestational age (significantly more women at $<26$ weeks' gestation were randomized to atosiban).

A Cochrane review of six trials including 1,695 patients receiving tocolysis with atosiban failed to demonstrate the superiority of the oxytocin receptor antagonist over $\beta 2$-agonists or placebo in terms of tocolytic efficacy or infant outcomes. ${ }^{28}$ Use of atosiban resulted in lower infant birth weight (weighted mean difference $-138.31 \mathrm{~g}$; $95 \%$ CI -248.76 to -27.86$)$ and more maternal adverse drug reactions (RR 4.02; 95\% CI 2.05-7.85, two trials, 613 women). Compared with $\beta 2$-agonists, atosiban increased the numbers of infants born under $1,500 \mathrm{~g}$ (RR 1.96; 95\% CI 1.15-3.35, two trials, 575 infants). ${ }^{28}$ The recent comprehensive network meta-analysis found that atosiban, while better than placebo in delaying delivery at 48 hours (odds ratio 2.02; 95\% CI 1.1-3.8), had a lower probability of being superior to other tocolytics. ${ }^{8}$ Given the biologic plausibility and good maternal safety profile, one would hope for further well designed, randomized, placebo-controlled trials to evaluate this group of tocolytics.

\section{Prostaglandin inhibitors}

Prostaglandins, derived from the sequential oxidation of arachidonic acid via prostaglandin synthase or cyclooxygenase, are paracrine hormones that act on a variety of cells and have a multitude of functions. Prostaglandins affect uterine muscle contraction by enhancing formation of myometrial gap junctions, causing an increase in free intracellular calcium levels and amplifying activation of myosin light chain kinase. Indomethacin is the prostaglandin inhibitor most frequently used for tocolysis and achieves its effect by reversibly binding to cyclooxygenase.

Indomethacin is usually administered orally as a $50 \mathrm{mg}$ loading dose followed by 25-50 mg orally every 6 hours for up to 48 hours. Because of its side effect profile, its use is limited to preterm labor prior to 32 weeks' gestation in women with normal renal function and normal amniotic fluid volume.

A 2005 Cochrane review (updated in 2010) of prostaglandin inhibitors in the treatment of preterm labor included three trials that compared prostaglandin inhibitors with placebo. One small trial resulted in a statistically significant reduction in the number of women delivering earlier than 37 weeks' gestation (RR 0.21; 95\% CI 0.07-0.62; number needed to treat 2 [CI 1-3]). Data from two trials that included 70 women showed a trend towards a reduction in delivery before 37 weeks' gestation if within 48 hours of initiation of treatment (RR $0.20,95 \%$ CI $0.03-1.28$ ) or within 7 days (RR 0.41; CI 0.1-1.66). The authors warn that all estimates of effect are imprecise and need to be interpreted with caution due to small numbers. ${ }^{29}$ The results of a hypothetical cohort of 1,000 women receiving prostaglandin inhibitors in a 2009 meta-analysis demonstrated that only 80 would deliver within 48 hours, compared with 182 for the next best treatment, suggesting that prostaglandin inhibitors should be considered first-line for preterm labor prior to 37 weeks' gestation. ${ }^{9}$ The recent network meta-analysis found that prostaglandin inhibitors were more efficacious in delaying delivery by 48 hours (odds ratio 5.94, 95\% credible interval 2.14-12.34) when compared with placebo. ${ }^{8}$ Further, prostaglandin inhibitors had a greater beneficial effect than any other tocolytic, and a $96 \%$ probability of being ranked in the top three most efficacious tocolytics. ${ }^{8}$

\section{Nitrates and other drugs}

Early tocolytic agents included alcohol. Historically this was utilized with some effectiveness but the maternal and infant adverse effects outweighed any benefits. With the advent of newer agents, such as those listed above, use of alcohol fell out of favor in the 1970s.

Nitrate drugs are advocated based on observations in animals that nitric oxide synthase activity was correlated with labor, but functional studies in humans were contradictory. Eight randomized trials (including 466 women) utilizing nitric oxide donors as tocolytics were identified in a Cochrane review of the subject. ${ }^{30}$ Only one of these trials compared a nitrate with placebo. No differences were found in the rate of prolongation of pregnancy for 48 hours (RR 3.06, 95\% CI $0.74-12.63$ versus placebo; RR $1.43,95 \%$ CI $0.47-4.37$ versus other tocolytics). Nitrates did reduce the risk of delivering before 37 weeks' gestation (RR 0.69, 95\% CI 0.53-0.88) and had fewer adverse drug reactions compared with other tocolytic agents (RR $0.47,95 \%$ CI $0.37-0.61) .{ }^{30}$ However, it was concluded that there were insufficient data to determine 
whether nitric oxide donors are effective given that the number of trials reporting each outcome was small. Use of these agents is thus limited to investigative trials. The recent network meta-analysis determined that nitrates would only have a $4 \%$ chance of being the best agent to delay delivery for 48 hours and a $10 \%$ probability of being the best agent with regard to fewer maternal side effects. ${ }^{8}$

Progesterone therapy can be used as a preventive strategy to reduce the rate of preterm birth in selected high-risk populations. ${ }^{31}$ However, only a few trials have evaluated the use of a progestational agent for acute tocolysis. These trials had some methodological issues, including administration with other tocolytics. The studies generally did not report on 48-hour delay of delivery as well. Thus, the Cochrane review on this subject found insufficient evidence to advocate progestational agents as tocolytic agents. ${ }^{32}$

Tocolytic trials generally use a drug from one of the above classes of medication. There are not many other drugs studied in the area of tocolysis. Ifenprodil, a selective alpha inhibitor, has been utilized in one small French trial but was less effective than ritodrine. ${ }^{33}$

\section{General pharmacological considerations related to tocolytics in pregnancy}

When selecting a tocolytic, patient-specific characteristics must be considered. In patients who require magnesium sulfate for neuroprotection, it may be suitable to use this therapy at tocolytic doses because it can serve both purposes. ${ }^{34}$ Indomethacin should be reserved for pregnancies that are less than 32 weeks' gestation to avoid the risk of premature closure of the ductus arteriosus. ${ }^{35}$

Personalized tocolytic therapy should also account for individual patient differences in drug metabolism and response. Interindividual variability in response may be due to differences in patient genetics or environmental factors. We have reported that nifedipine clearance is altered in patients with cytochrome $\mathrm{P} 450$ (CYP)3A5 polymorphism. ${ }^{36}$ Women of African American descent are more likely than Caucasians to express an active form of CYP3A5, which may increase the metabolism of nifedipine. Pregnancy is also known to alter drug disposition. For instance, in a healthy pregnant woman, creatinine clearance increases 1.5 -fold during pregnancy. ${ }^{37}$ This may increase clearance of drugs such as magnesium. Concomitant diseases must also be considered when selecting treatment. For instance, magnesium and indomethacin should be avoided in women with impaired renal function.

\section{Summary and conclusion}

Short-term use of tocolytic drugs is common in order to prolong pregnancy long enough for effective antenatal corticosteroids and other therapies to be administered. Multiple classes and drugs are utilized, mainly because many demonstrate similar efficacy. ${ }^{2}$ Recent systematic reviews and meta-analyses have demonstrated that prostaglandin inhibitors tend to have the best probability of delaying delivery by at least 48 hours, while calcium channel blockers may be superior in preventing neonatal complications. ${ }^{8} 9$ However, these results are from meta-analyses and not direct trials using all drug classes and thus must be interpreted carefully. In addition, because of concerns about premature closure of the fetal ductus, prostaglandin inhibitors are seldom used in practice after 32 weeks.

Short-term tocolytic therapy should be individualized to the patient and her particular circumstances and the potential for side effect. Pharmacogenetic principles have been explored in relation to tocolytic drugs like nifedipine. . $^{36,38,39}$ These may give us a glimpse into the future of obstetric therapeutics and more individualization of pharmacotherapy during pregnancy. ${ }^{40}$

No matter which tocolytic agent the clinician chooses, the evidence supports the use of short-term tocolytic drugs to prolong pregnancy for at least 48 hours to allow for administration of antenatal steroids. This may also allow for transport of the mother to a tertiary care facility and for administration of magnesium sulfate to reduce the risk of cerebral palsy. While many trials have used tocolytics for longer periods of time, those that analyzed prolonged courses of tocolytics have generally failed to demonstrate benefit. ${ }^{41}$ So while the choice of first-line agent may not be clear, it is evident that short-term tocolysis is an effective and helpful therapy for women in preterm labor.

\section{Acknowledgments}

The contribution of DMH to this work was partially supported by a grant from the Eunice Kennedy Shriver National Institute of Child Health and Human Development to the Obstetric-Fetal Pharmacology Research Units Network \#5U10HD063094. The contribution of SKQ was partially supported by grant \#5K23HD071134. The views expressed in this manuscript represent those of the authors and are not necessarily those of the National Institutes of Health.

\section{Disclosure}

None of the authors has any financial conflicts of interest concerning the material presented in this paper. 


\section{References}

1. Martin JA, Hamilton BE, Ventura SJ, Osterman M, Mathews TJ. Births: final data for 2011. National Vital Statistics Reports. Volume 62. Hyattsville, MD, USA: National Center for Health Statistics; 2013.

2. American College of Obstetricians and Gynecologists; Committee on Practice Bulletins-Obstetrics. ACOG practice bulletin no 127: management of preterm labor. Obstet Gynecol. 2012;119(6):1308-1317.

3. MacDorman MF, Callaghan WM, Mathews TJ, Hoyert DL, Kochanek KD. Trends in preterm-related infant mortality by race and ethnicity, United States, 1999-2004. Int J Health Serv. 2007;37(4): 635-641.

4. Mathews TJ, MacDorman MF. Infant mortality statistics from the 2007 period linked birth/infant death data set. Natl Vital Stat Rep. 2011;59(6):1-30.

5. Petrou $\mathrm{S}$. The economic consequences of preterm birth during the first 10 years of life. BJOG. 2005;112 Suppl 1:10-15.

6. Institute of Medicine. Preterm Birth: Causes, Consequences, and Prevention. Washington, DC, USA: National Academies Press; 2006.

7. Crowley P. Prophylactic corticosteroids for preterm birth. Cochrane Database Syst Rev. 2000;2:CD000065.

8. Haas DM, Caldwell DM, Kirkpatrick P, McIntosh JJ, Welton NJ. Tocolytic therapy for preterm delivery: systematic review and network meta-analysis. BMJ. 2012;345:e6226.

9. Haas DM, Imperiale TF, Kirkpatrick PR, Klein RW, Zollinger TW, Golichowski AM. Tocolytic therapy: a meta-analysis and decision analysis. Obstet Gynecol. 2009;113(3):585-594.

10. Creasy RK, Resnik R, Iams JD. Creasy and Resnik's Maternal Fetal Medicine: Principles and Practice. 6th ed. Philadelphia, PA, USA: Saunders; 2009.

11. US Food and Drug Administration. Terbutaline: Label change - warnings against use for treatment of preterm labor. 2001. Available from: http://www.fda.gov/Safety/MedWatch/SafetyInformation/SafetyAlert sforHumanMedicalProducts/ucm243843.htm. Accessed December 17, 2013.

12. Berg G, Andersson RG, Ryden G. Beta-adrenergic receptors in human myometrium during pregnancy: changes in the number of receptors after beta-mimetic treatment. Am J Obstet Gynecol. 1985;151(3):392-396.

13. Anotayanonth S, Subhedar NV, Garner P, Neilson JP, Harigopal S. Betamimetics for inhibiting preterm labour. Cochrane Database Syst Rev. 2004;4:CD004352.

14. Perry KG Jr, Morrison JC, Rust OA, Sullivan CA, Martin RW, Naef RW 3rd. Incidence of adverse cardiopulmonary effects with low-dose continuous terbutaline infusion. Am J Obstet Gynecol. 1995;173(4):1273-1277.

15. BenedettiTJ. Maternal complications of parenteral beta-sympathomimetic therapy for premature labor. Am J Obstet Gynecol. 1983;145(1):1-6.

16. Ozcan T, Turan C, Ekici E, et al. Ritodrine tocolysis and neonatal intraventricular-periventricular hemorrhage. Gynecol Obstet Invest. 1995;39(1):60-62.

17. Palta M, Sadek M, Lim TS, Evans M, McGuinness G. Association of tocolytic therapy with antenatal steroid administration and infant outcomes. Newborn Lung Project. Am J Perinatol. 1998;15(2):87-92.

18. Conde-Agudelo A, Romero R, Kusanovic JP. Nifedipine in the management of preterm labor: a systematic review and metaanalysis. Am J Obstet Gynecol. 2011;204(2):134. e1-e20.

19. Nassar AH, Aoun J, Usta IM. Calcium channel blockers for the management of preterm birth: a review. Am J Perinatol. 2011;28(1):57-66.

20. King JF, Flenady VJ, Papatsonis DN, Dekker GA, Carbonne B. Calcium channel blockers for inhibiting preterm labour. Cochrane Database Syst Rev. 2003;1:CD002255.

21. Steer CM, Petrie RH. A comparison of magnesium sulfate and alcohol for the prevention of premature labor. Am J Obstet Gynecol. $1977 ; 129(1): 1-4$.
22. Elliott JP. Magnesium sulfate as a tocolytic agent. Am J Obstet Gynecol. 1983;147(3):277-284.

23. Madden C, Owen J, Hauth JC. Magnesium tocolysis: serum levels versus success. Am J Obstet Gynecol. 1990;162(5):1177-1180.

24. Goldenberg RL. The management of preterm labor. Obstet Gynecol. 2002;100(5 Pt 1):1020-1037.

25. Mercer BM, Merlino AA. Magnesium sulfate for preterm labor and preterm birth. Obstet Gynecol. 2009;114(3):650-668.

26. Worldwide Atosiban versus Beta-agonists Study Group. Effectiveness and safety of the oxytocin antagonist atosiban versus beta-adrenergic agonists in the treatment of preterm labour. The Worldwide Atosiban versus Beta-agonists Study Group. BJOG. 2001;108(2):133-142.

27. Romero R, Sibai BM, Sanchez-Ramos L, et al. An oxytocin receptor antagonist (atosiban) in the treatment of preterm labor: a randomized, double-blind, placebo-controlled trial with tocolytic rescue. Am JObstet Gynecol. 2000;182(5):1173-1183.

28. Papatsonis D, Flenady V, Cole S, Liley H. Oxytocin receptor antagonists for inhibiting preterm labour. Cochrane Database Syst Rev. 2005;3:CD004452

29. King J, Flenady V, Cole S, Thornton S. Cyclo-oxygenase (COX) inhibitors for treating preterm labour. Cochrane Database Syst Rev. 2005;2:CD001992.

30. Duckitt K, Thornton S. Nitric oxide donors for the treatment of preterm labour. Cochrane Database Syst Rev. 2002;3:CD002860.

31. Committee on Practice Bulletins-Obstetrics, The American College of Obstetricians and Gynecologists. Practice bulletin no 130: prediction and prevention of preterm birth. Obstet Gynecol. 2012;120(4):964-973.

32. Su LL, Samuel M, Chong YS. Progestational agents for treating threatened or established preterm labour. Cochrane Database Syst Rev. 2010;1:CD006770.

33. Breart G, Sureau C, Rumeau-Rouquette C. [A study of the comparative efficiency of ifenprodil and ritodrine in the treatment of threatened premature labour]. J Gynecol Obstet Biol Reprod (Paris). 1979;8(3):261-263. French.

34. Crowther CA, Hiller JE, Doyle LW, Haslam RR. Effect of magnesium sulfate given for neuroprotection before preterm birth: a randomized controlled trial. JAMA. 2003;290(20):2669-2676.

35. Abou-Ghannam G, Usta IM, Nassar AH. Indomethacin in pregnancy: applications and safety. Am J Perinatol. 2012;29(3):175-186.

36. Haas DM, Quinney SK, Clay JM, et al. Nifedipine pharmacokinetics are influenced by CYP3A5 genotype when used as a preterm labor tocolytic. Am J Perinatol. 2013;30(4):275-281.

37. Abduljalil K, Furness P, Johnson TN, Rostami-Hodjegan A, Soltani H. Anatomical, physiological and metabolic changes with gestational age during normal pregnancy: a database for parameters required in physiologically based pharmacokinetic modelling. Clin Pharmacokinet. 2012;51(6):365-396.

38. Haas DM, Quinney SK, McCormick CL, Jones DR, Renbarger JL. A pilot study of the impact of genotype on nifedipine pharmacokinetics when used as a tocolytic. J Matern Fetal Neonatal Med. 2012;25(4):419-423.

39. Quinney SK, Mohamed AN, Hebert MF, et al. A semi-mechanistic metabolism model of CYP3A substrates in pregnancy: predicting changes in midazolam and nifedipine pharmacokinetics. CPT Pharmacometrics Syst Pharmacol. 2012;1:e2.

40. Haas DM, D'Alton M. Pharmacogenetics and other reasons why drugs can fail in pregnancy: higher dose or different drug? Obstet Gynecol. 2012;120(5):1176-1179.

41. Lyell DJ, Pullen KM, Mannan J, et al. Maintenance nifedipine tocolysis compared with placebo: a randomized controlled trial. Obstet Gynecol. 2008;112(6):1221-1226. 
International Journal of Women's Health

Dovepress

\section{Publish your work in this journal}

The International Journal of Women's Health is an international, peerreviewed open-access journal publishing original research, reports, editorials, reviews and commentaries on all aspects of women's healthcare including gynecology, obstetrics, and breast cancer. The manuscript management system is completely online and includes Visit http://www.dovepress.com/testimonials.php to read real quotes from published authors.

Submit your manuscript here: http://www.dovepress.com/international-journal-of-womens-health-journal 